\title{
OPTIMALISASI MEMBANGUN BRAND IMAGE TERHADAP CUSTOMER LOYALTY MELALUI CUSTOMER VALUE DAN CUSTOMER RETENTION SEBAGAI VARIABEL INTERVENING \\ Ratih Amelia ${ }^{1}$ \\ Politeknik Unggul LP3M \\ rameliaaque1217@yahoo.com
}

\author{
Selfitrida Ayani ${ }^{2}$ \\ Politeknik Unggul LP3M \\ selfitridaa.yani@yahoo.com
}

\section{DOI: https://doi.org/10.33592/jeb.v26i1.659}

Abstract

Private tertiary institutions are currently being demanded to continue to make improvements both internally and externally. The unfamiliar image of the campus makes it difficult for universities to compete. This is often the case with LP3M Superior Polytechnics. Where the perception of people still studying college must be at the University, High School and Academy. Then all this time the term Polytechnic is still unknown to many people. One of the efforts made by the management of the LP3M Superior Polytechnic is to maximize the admission program by giving rewards or better known as member get member (MGM). The main focus in this research is to analyze directly 1) brand image to customer value, 2) analyze brand image to customer retention. Furthermore, indirectly analyze 1) brand image of customer loyalty through customer value 4) brand image of customer loyalty through customer retention. This research approach is path analysis. The population in this study were active students in the 2018/2019 school year on the LP3M Superior Polytechnic campus which consisted of 5 study programs totaling 316. While the method of determining the sample with non-probability sampling was accidental sampling. Where researchers took 250 active students to be sampled. Data collection using a questionnaire with a Likert scale.

The results showed that directly 1) brand image had a significant effect on customer value, 2) brand image had a significant effect on customer retention. While indirectly 3) brand image has no significant effect on customer loyalty through customer value, 4) brand image has a significant effect on customer loyalty through customer retention.

Keywords: Brand Image, Value, Retention, Loyalty

\begin{abstract}
Abstrak
Perguruan tinggi swasta pada saat sekarang ini terus dituntut untuk terus melakukan upaya perbaikan baik yang terjadi secara internal dan ekternal. Belum terkenalnya citra kampus menyebabkan perguruan tinggi akan sangat sulit bersaing. Hal inilah yang sering terjadi pada Politeknik Unggul LP3M. Dimana persepsi orang masih menggap kuliah harus di Universitas, Sekolah Tinggi dan Akademi. Kemudian selama ini istilah Politeknik masih asing dibenak orang banyak. Salah satu upaya yang dilakukan manajemen Politeknik Unggul LP3M yaitu dengan memaksimalkan program penerimaan mahasiswa baru melalui pemberian reward atau lebih dikenal dengan istilah member get member (MGM). Fokus utama dalam penelitian ini yaitu untuk menganalisis secara langsung 1) brand image terhadap customer value, 2) menganalisis brand image terhadap customer retention. Selanjutnya menganalisis secara tidak langsung 1) brand image terhadap customer loyalty melalui customer value 4) brand image terhadap customer loyalty melalui customer retention. Pendekatan penelitian ini yaitu analisis jalur. Populasi dalam penelitian ini mahasiswa aktif pada tahun ajaran 2018/2019 pada kampus Politeknik
\end{abstract}


Unggul LP3M yang terdiri dari 5 program studi yang berjumlah 316. Sedangkan metode penentuan sampel dengan non probability sampling yaitu dengan cara accidental sampling. Dimana peneliti mengambil 250 mahasiswa aktif untuk dijadikan sampel. Pengumpulan data menggunakan kuesioner dengan skala likert.

Hasil penelitian menunjukkan bahwa secara langsung 1) brand image berpengaruh signifikan terhahadap customer value, 2) brand image berpengaruh signifikan terhahadap customer retention. Sedangkan secara tidak langsung 3) brand image tidak berpengaruh signifikan terhahadap customer loyalty melalui customer value, 4) brand image berpengaruh signifikan terhahadap customer loyalty melalui customer retention.

\section{Kata Kunci: Brand Image, Value, Retention, Loyalty}

\section{A. Pendahuluan}

Perguruan tinggi merupakan salah satu tempat dimana harapan setiap orang untuk meraih kehidupan yang lebih baik. Loyalitas mahasiswa juga dapat memiliki arti yang sangat penting bagi perguruan tinggi swasta. Sebagai seorang mahasiswa atau konsumen tentunya akan memiliki tingkat harapan yang berbeda. Hal ini terjadi karena perbedaan motivasi dan karakeristik seorang individu. Selanjutnya mahasiswa yang memiliki nilai kognetif yang baik ia akan membandingkan antara total pengorbanan yang disumbangkan dengan total manfaat yang ia dapatkan.

Loyalitas konsumen sebagaimana diketahui bahwa tujuan dari suatu bisnis adalah untuk menciptakan para pelanggan merasa puas. Menurut (Kotler \& Keller, 2012) adalah komitmen yang dipegang secara mendalam untuk membeli atau mendukung kembali produk atau jasa yang disukai di masa depan meski pengaruh situasi dan usaha pemasaran berpotensi menyebabkan pelanggan berahli. Sedangkan menurut (Subagio, 2015) berpendapat bahwa loyalitas merupakan pembelian ulang sebuah merek secara konsisten oleh konsumen. Istilah loyalitas sudah sering diperdengarkan oleh pakar marketing maupun praktisi bisnis, loyalitas merupakan konsep yang tampak mudah dibicarakan dalam konteks sehari-hari, tetapi menjadi lebih sulit ketika dianalisis maknanya. Menurut (Kartajaya, 2007) menyatakan faktor loyalitas pelanggan sebagai berikut kepuasan pelanggan, retensi pelanggan, migrasi pelanggan, antusiasme pelanggan, spiritualitas pelanggan.

Banyak faktor yang mempengaruhi loyalitas seorang mahasiswa. Brand image memiliki peran yang penting dalam membentuk loyalitas pelanggan. Brand image yang melekat pada perguruan tinggi dianggap memiliki peran yang sangat penting dari strategi penerimaan mahasiswa baru. Citra merek perguruan tinggi 
merupakan cerminan akan persepsi calon mahasiswa terhadap suatu produk atau jasa. Menurut (Hasan, 2013) menjelaskan bahwa brand image atau citra merek merupakan serangkaian sifat tangible dan intangible, seperti ide, keyakinan, nilai-nilai, kepentingan, dan fitur yang membuatnya menjadi unik. Citra merek memang tidak terlihat dengan kasat mata. Namun citra merek memiliki arti penting bagi suatu perguruan tinggi. Semakin positif citra perguruan tinggi akan mendorong seorang konsumen untuk melakukan keputusan memilih perguruan tinggi tersebut. Sebalik jika citra suatu perguruan tinggi negatif maka akan mendorong calon mahasiswa akan menninggalkannya (Nasib \& Amelia, 2018).

$$
\text { Faktor selanjutnya yang }
$$
mempengaruhi loyalitas mahasiswa yaitu customer value. Menurut (I \& J, 2009) Customer value adalah nilai yang dirasakan pelanggan sebagai dua bagian konsep yang terdiri dari manfaat yang diterima (economic, social dan relational) dan pengorbanan yang dilakukan (price, time, effort, risk dan convenience) oleh pelanggan. Sedangkan menurut Zeithaml dalam (Tjiptono, 2011) mendifinisikan nilai pelanggan sebagai penilaian keseluruhan pelanggan terhadap utilitas sebuah produk berdasarkan persepsinya terhadap apa yang diterima dan apa yang diberikan. Customer value memiliki 3 dimensi, yaitu functional value, emotional value dan social value. Menurut (Soliha, 2015) menyatakan bahwa nilai pelanggan sebagai seorang mahasiswa sering kali akan memiliki rasa kepedulian terhadap perguruan tingginya. Dimana jika akan orang lain yang mengatakan berita atau isu tidak benar, maka mahasiswa tersebut akan membela dan menjelaskan akan kondisi yang sebenarnya. Sehingga dengan adanya program penerimaan mahasiswa baru dengan adanya reward berupa penghargaan tentunya membuat mahasiswa lebih termotivasi. Nilai pelanggan juga terkait dengan tingkat retensi para mahasiwa. Dimana seorang mahasiswa yang merasa puas dengan nilai yang diterimanya tentunya akan memiliki rasa memiliki terhadap perguruan tinggi tersebut. Menurut studi yang dilakukan oleh (Felania, 2018) menyatakan bahwa retensi pelanggan memiliki pengaruh positif dan signifikan terhadap loyalitas pelanggan. Retensi pelanggan akan memberikan nilai manfaat terhadap perusahaan.

Strategi retensi pelanggan difokuskan pada teknik - teknik yang digunakan untuk 
mempertahankan pelanggan agar pelanggan tidak beralih pada pemasok atau perusahan jasa yang lain. Menurut (Tjiptono, 2011) ada enam faktor yang merupakan manfaat ekonomik dalam mempertahankan pelanggan yaitu biaya akuisisi pelanggan baru, profit dasar, pertumbuhan pendapatan, penghematan biaya, referrals, harga premium. Retensi pelanggan akan memiliki beberapa manfaat tersendiri bagai suatu perusahaan. Dimana manfaat tersebut akan dinikmati baik dalam hal finansial maupun nonfinansial. Menurut (Kotler \& Keller, 2012) ada 3 dimensi untuk membangun Retensi Pelanggan yaitu financial benefits, social benefits dan structural ties.

Politeknik Unggul LP3M merupakan salah satu dari sekian banyak perguruan tinggi swasta yang ada di Kota Medan. Tingginya angka persaingan yang terjadi membuat manajemen untuk terus meningkatkan loyalitas para mahasiswa melalui kegiatan MGM dalam kegiatan penerimaan mahasiswa baru. Berdasarkan data yang ada mengenai hasil MGM (Member Get Member) yang ada di Politeknik Unggul LP3M selama 3 tahun terakhir.

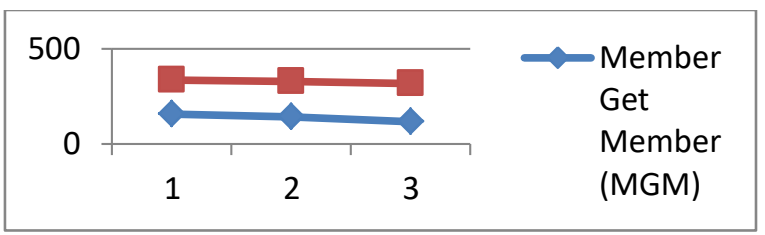

Sumber: Politeknik Unggul LP3M Medan (2019)

\section{Gambar 1: Daftar MGM}

Berdasarkan gambar 1 di atas diketahui bahwa selama 3 tahun terakhir jumlah mahasiswa terus mengalami penurunan. Dimana tahun 2016 sebanyak 335 orang dengan $158 \mathrm{mgm}$, sedangkan tahun 2018 jumlah mahasiswa turun menjadi 316 dengan $117 \mathrm{mgm}$. Selanjutnya observasi awal yang peneliti lakukan bahwa selama ini mahasiswa masih sulit untuk mendapat reward MGM yang ditawarkan manajemen Politeknik Unggul LP3M. salah satu masalah yang sering muncul yaitu masalah brand image dimana selama ini kampus Politeknik Unggul LP3M belum dikenal oleh masyarakat luas, identik dengan kampus kampus Politeknik LP3I. Selanjutnya selama ini persepsi nilai mahasiswa yang ada tidak selalu tercapai dimana uang kuliah yang dianggap mahal belum sebanding dengan kompetensi yang diterima. Akan tetapi disatu sisi manajemen dan yayasan selalu mengharapkan untuk mahasiswa aktif dalam merekoemendasikan keluarga dan teman kuliah. 


\section{B. Metode Penelitian}

Pendekatan penelitian ini merupakan analisis jalur. Lokasi penelitian ini dilakukan pada Politeknik Unggul LP3M yang beralamat pada $\mathrm{Jl}$ Iskandar Muda No 3 CDEF Medan. Populasi dalam penelitian ini mahasiswa aktif pada tahun ajaran 2018/2019 pada kampus Politeknik Unggul LP3M yang terdiri dari 5 program studi yang berjumlah 316. Sedangkan metode penentuan sampel dengan non probability sampling yaitu dengan cara accidental sampling. Dimana peneliti mengambil 250 mahasiswa aktif untuk dijadikan sampel. Sumber data penelitian ini yakni data primer yang diperoleh dengan melakukan wawancara (interview) dan menyebarkan daftar pertanyaan (questionaire) serta data sekunder diperoleh dari studi dokumentasi berupa dokumen-dokumen resmi yang diterbitkan Politeknik Unggul LP3M. Sedangkan teknik analisis data yang digunakan dalam penelitian ini, yaitu

\section{Analisis Jalur (Path Analisis)}

Model persamaan regresi linear berganda adalah seperti berikut ini :

Persamaan Pertama :

Customer Loyalty $=\mathrm{a}_{1}+\mathrm{C}_{\text {Brand Image }}$

Persamaan Kedua :

Customer Value $=\mathrm{a}_{2}+\mathrm{a}_{\mathrm{Brand}}$ Image
Persamaan Ketiga:

Customer Retention $=\mathrm{a}_{3}+\mathrm{a}_{\text {Brand Image }}$

Persamaan Keempat:

Customer Loyalty $=\mathrm{a}_{4}+\mathrm{C}_{\text {Brand Image }}$

$+\mathrm{b}_{\text {Customer value }}+\mathrm{b}_{\text {Customer retention }}$

\section{Hasil Penelitian Dan Pembahasan}

\section{Gambaran Umum Responden}

Karakteristik responden pada penelitian ini terdiri dari jenis kelamin, tingkat pendidikan dan usia.

a. Karakteristik

Responden Berdasarkan Jenis Kelamin

Gambaran umum responden yang ada dalam penelitian ini adalah mahasiswa Politeknik Unggul LP3M berdasarkan jenis kelamin, dapat dilihat pada Tabel 1 berikut :

Tabel 1:

Karakteristik Responden Berdasarkan Jenis Kelamin

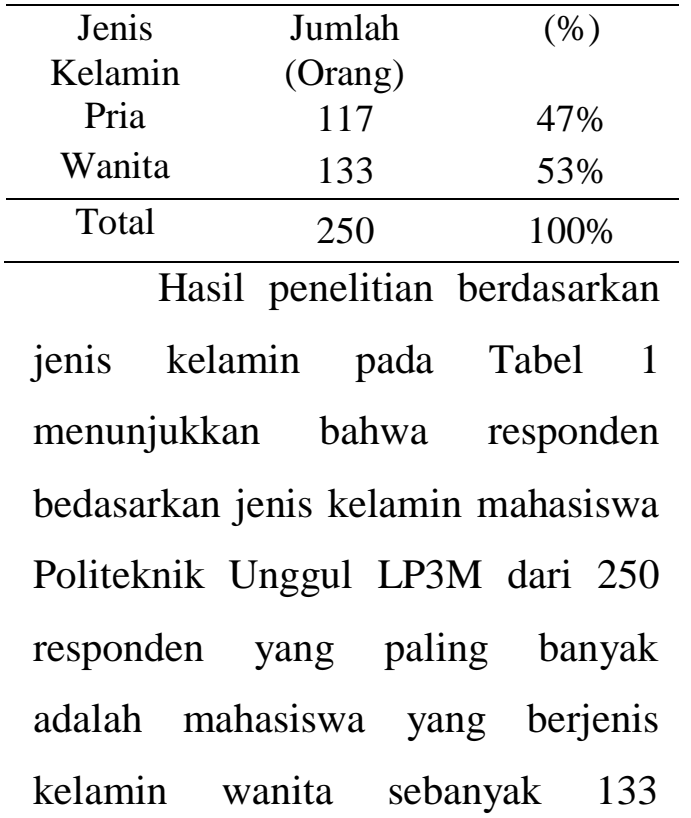


responden (47\%) sedangkan pria yang berjumlah 117 orang (53\%).

\section{b. Karakteristik}

Responden

\section{Berdasarkan Tingkat Pendidikan}

Gambaran umum responden yang ada dalam penelitian ini adalah mahasiswa Politeknik Unggul LP3M berdasarkan tingkat pendidikan, dapat dilihat pada Tabel 2 berikut :

Tabel 2

Karakteristik Responden Berdasarkan Tingkat Pendidikan

\begin{tabular}{ccc}
\hline $\begin{array}{c}\text { Jenis } \\
\text { Kelamin }\end{array}$ & $\begin{array}{c}\text { Jumlah } \\
\text { (Orang) }\end{array}$ & $(\%)$ \\
SMU & 250 & $100 \%$ \\
DIPLOMA & 0 & $0 \%$ \\
S1 & 0 & $0 \%$ \\
S2 & 0 & $0 \%$ \\
\hline Jumlah & 52 & $100 \%$ \\
\hline
\end{tabular}

Hasil penelitian berdasarkan

jenis kelamin pada Tabel 2 menunjukkan bahwa responden bedasarkan tingkat pendidikan mahasiswa Politeknik Unggul LP3M dari 250 responden yang paling banyak adalah mahasiswa berpendidikan SMA sebanyak 250 responden (100\%).

\section{c. Karakteristik \\ Responden}

\section{Berdasarkan Usia}

Gambaran umum responden yang ada dalam penelitian ini adalah mahasiswa Politeknik Unggul LP3M berdasarkan usia, dapat dilihat pada Tabel 3 berikut :

Tabel 3

\section{Karakteristik Responden Berdasarkan} Usia

\begin{tabular}{ccc}
\hline Usia (Tahun) & Jumlah (Orang) & $(\%)$ \\
$<25$ & 100 & $100 \%$ \\
$25-35$ & 0 & $0 \%$ \\
$36-45$ & 0 & $0 \%$ \\
$>45$ & 0 & $0 \%$ \\
\hline Total & 250 & $100 \%$ \\
\hline
\end{tabular}

Hasil penelitian berdasarkan tingkat usia pada Tabel 3 menunjukkan bahwa dari jumlah responden yang diteliti sebanyak 250 orang usia mahasiswa Politeknik Unggul LP3M yang paling banyak didominan adalah usia $<25$ tahun sebanyak 250 responden $(100 \%)$.

\section{Uji Insrumen Penelitian}

\section{a. Uji Validitas}

\section{1) Variabel Brand image $\left(X_{1}\right)$}

Hasil uji validitas variabel brand image sebagai berikut:

\section{Tabel 4}

\section{Hasil Uji Validitas Brand Image (X)}

\begin{tabular}{cccc}
\hline Pernyataan & $\begin{array}{c}\text { Corrected Item Total } \\
\text { Correlation } \\
\left(\boldsymbol{r}_{\text {hitung }}\right)\end{array}$ & $\mathbf{r}_{\text {tabel }}$ & Validitas \\
Item 1 & 0.503 & 0,273 & Valid \\
Item 2 & 0.614 & 0,273 & Valid \\
Item 3 & 0.647 & 0,273 & Valid \\
Item 4 & 0.616 & 0,273 & Valid \\
Item 5 & 0.435 & 0,273 & Valid \\
Item 6 & 0.523 & 0,273 & Valid \\
Item 7 & 0.656 & 0,273 & Valid \\
Item 10 & 0.592 & 0,273 & Valid \\
\hline
\end{tabular}

Sumber: Hasil Pengolahan SPSS (2020) 
Berdasarkan Tabel 4 di atas diketahui nilai validitas pernyataan untuk brand image seluruhnya sudah valid karena nilai validitas seluruhnya lebih besar dari $\mathrm{r}_{\text {tabel }}(\mathrm{n}-2=250$ 2=248=0,273). Diketahui bawah total seluruhnya nilai $r_{\text {hitung }}>r_{\text {tabel. }}$. Dengan demikian dapat disimpulkan bahwa seluruh item pernyataan dari brand image dinyatakan valid dan dapat digunakan dalam penelitian selanjutnya.

\section{2) Variabel Custumer Value ( $\left.\mathbf{Y}_{1}\right)$}

Hasil uji validitas variabel Custumer Value sebagai berikut:

\section{Tabel 5}

Hasil Uji Validitas Custumer Value $\left(\mathbf{X}_{2}\right)$

\begin{tabular}{cccc}
\hline Pernyataan & $\begin{array}{c}\text { Corrected Item } \\
\text { Total Correlation } \\
\left(\boldsymbol{r}_{\text {hitung }}\right)\end{array}$ & $\mathbf{r}_{\text {tabel }}$ & Validitas \\
Item 1 & 0.515 & 0,273 & Valid \\
Item 2 & 0.608 & 0,273 & Valid \\
Item 3 & 0.636 & 0,273 & Valid \\
Item 4 & 0.568 & 0,273 & Valid \\
Item 5 & 0.569 & 0,273 & Valid \\
Item 6 & 0.659 & 0,273 & Valid \\
Item 7 & 0.575 & 0,273 & Valid \\
Item 8 & 0.683 & 0,273 & Valid \\
\hline
\end{tabular}

Sumber: Hasil Pengolahan SPSS (2020)

Berdasarkan Tabel 5 di atas diketahui nilai validitas pernyataan untuk Custumer Value seluruhnya sudah valid karena nilai validitas seluruhnya lebih besar dari $\quad \mathrm{r}_{\text {tabel }} \quad(\mathrm{n}-2=250-\quad 2=248=0,273)$. Diketahui bawah total seluruhnya nilai $\mathrm{r}_{\text {hitung }}$ $>r_{\text {tabel. }}$. Dengan demikian dapat disimpulkan bahwa seluruh item pernyataan dari
Custumer Value dinyatakan valid dan dapat digunakan dalam penelitian selanjutnya.

\section{3) Variabel Custmoer Retention $\left(\mathbf{Y}_{2}\right)$}

Hasil uji validitas variabel Customer Loyalty sebagai berikut:

Tabel 6

\section{Hasil Uji Validitas Custmoer Retention}

\begin{tabular}{cccc}
\multicolumn{4}{c}{$\left(\mathbf{Y}_{\mathbf{1}}\right)$} \\
\hline Pernyataan & $\begin{array}{c}\text { Corrected Item } \\
\text { Total Correlation } \\
\left(\boldsymbol{r}_{\text {hitung }}\right)\end{array}$ & $\mathbf{r}$ tabel & Validitas \\
Item 1 & 0.614 & 0,273 & Valid \\
Item 2 & 0.613 & 0,273 & Valid \\
Item 3 & 0.629 & 0,273 & Valid \\
Item 5 & 0.690 & 0,273 & Valid \\
Item 6 & 0.369 & 0,273 & Valid \\
Item 7 & 0.600 & 0,273 & Valid \\
Item 8 & 0.576 & 0,273 & Valid \\
\hline Sumber: Hasil Pengolahan SPSS (2020) &
\end{tabular}

Berdasarkan Tabel 6 di atas diketahui nilai validitas pernyataan untuk Customer retention seluruhnya sudah valid karena nilai validitas seluruhnya lebih besar dari $\quad r_{\text {tabel }} \quad(n-2=250-2=248=0,273)$. Diketahui bawah total seluruhnya nilai $\mathrm{r}_{\text {hitung }}$ $>r_{\text {tabel. }}$. Dengan demikian dapat disimpulkan bahwa seluruh item pernyataan dari customer retention kerja dinyatakan valid dan dapat digunakan dalam penelitian selanjutnya.

\section{4) Variabel Customer Loyalty $\left(\mathbf{Y}_{3}\right)$}

Hasil uji validitas variabel Customer Loyalty sebagai berikut: 


\section{Tabel 7}

\section{Hasil Uji Validitas Customer}

\section{Loyalty $\left(\mathbf{Y}_{2}\right)$}

\begin{tabular}{cccc}
\hline Pernyataan & $\begin{array}{c}\text { Corrected Item } \\
\text { Total Correlation } \\
\left(\boldsymbol{r}_{\text {hitung }}\right)\end{array}$ & $\mathbf{r}_{\text {tabel }}$ & Validitas \\
Item 1 & 0.575 & 0,273 & Valid \\
Item 2 & 0.439 & 0,273 & Valid \\
Item 3 & 0.666 & 0,273 & Valid \\
Item 4 & 0.549 & 0,273 & Valid \\
Item 5 & 0.732 & 0,273 & Valid \\
Item 6 & 0.640 & 0,273 & Valid \\
Item 7 & 0.739 & 0,273 & Valid \\
Item 8 & 0.608 & 0,273 & Valid \\
\hline
\end{tabular}

Sumber: Hasil Pengolahan SPSS (2020)

Berdasarkan Tabel 7 di atas diketahui nilai validitas pernyataan untuk Customer Loyalty seluruhnya sudah valid karena nilai validitas seluruhnya lebih besar dari $\quad \mathrm{r}_{\text {tabel }} \quad(\mathrm{n}-2=100-2=148=0,273)$. Diketahui bawah total seluruhnya nilai $r_{\text {hitung }}$ $>r_{\text {tabel }}$. Dengan demikian dapat disimpulkan bahwa seluruh item pernyataan dari Customer Loyalty dinyatakan valid dan dapat digunakan dalam penelitian selanjutnya.

\section{b. Uji Reliabilitas}

Hasil uji reliabilitas dalam penelitian ini sebagai berikut:

Tabel 8

\section{Hasil Uji Reliabilitas Instrumen}

\begin{tabular}{lc}
\hline \multicolumn{1}{c}{ Variabel } & Nilai Cronbach Alpha \\
Brand image (X) & 0,837 \\
Custumer Value (Y1) & 0,856 \\
Customer Retention (Y2) & 0,832 \\
Customer Loyalty (Y3) & 0,867 \\
\hline
\end{tabular}

Sumber: Hasil Diolah Peneliti (2020)
Berdasarkan tabel 8 di atas diketahui nilai Cronbach Alpha untuk semua variabel > 0,6. Sehingga dapat dinyatakan bahwa kelima variabel yaitu brand image dan custumer value, customer retention dan customer loyalty sudah handal.

\section{Hasil Penelitian Jalur}

Berdasarkan analisis jalur dari yang ada, maka dapat digambarkan

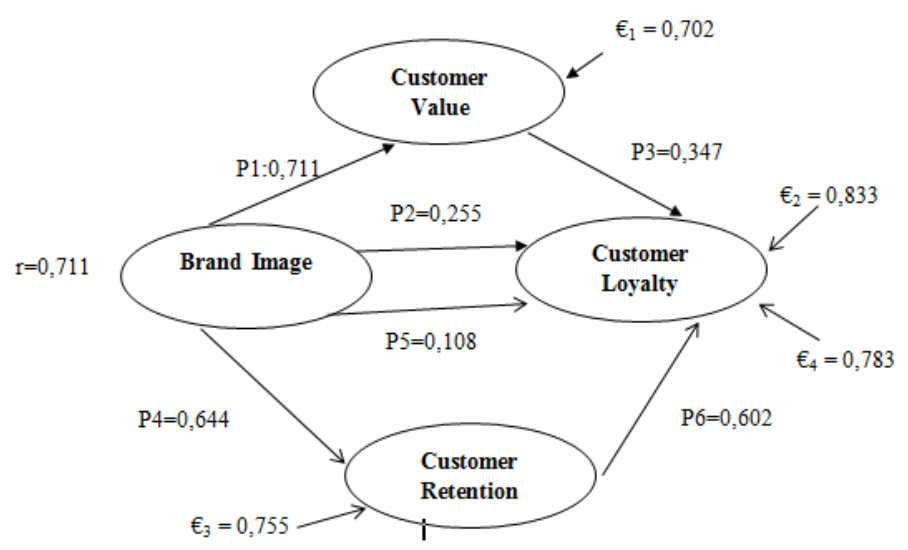

Gambar 2: Analisis Jalur

Hubungan Brand Image Terhadap Customer Loyalty Melalui Customer Value Dan Customer Retention

\section{Pengaruh Brand Image Terhadap Customer Value}

Hasil penelitian ini menunjukkan bahwa brand image berpengaruh positif dan signifikan terhadap customer value pada Politeknik Unggul LP3M. hal ini mendukung penelitian terdahulu yang dilakukan oleh (Felania, 2016) 
(Atstsaqifi, D.W, \& Listyorini, 2014) (Nasib \& Amelia, 2018) (Pusparani \& Rastini, 2014) (Emor \& Soegoto, 2015) (Indawati Lestari; Nasib, 2019) yang menyatakan bahwa brand image berpengaruh signifikan terhadap customer value. Hal ini menunjukkan bahwa ketika brand image semakin baik, maka akan berdampak pada peningkatan customer value. Implikasi temuan dalam penelitian ini menunjukkan bahwa selama ini kampus Politeknik Unggul LP3M tidak terindikasi melakukan transaksi jual beli ijazah kepada mahasiswa. Hal ini tentunya untuk terus dijaga agar masyarakat tetap memiliki persepsi yang baik akan brand imade kampus Politeknik Unggul LP3M.

\section{Pengaruh Brand Image Terhadap Retention}

Secara langsung brand image memiliki pengaruh signifikan terhadap terhadap customer retention pada Politeknik Unggul LP3M. Hal ini sesuai dengan hasil penelitian sebelumnya yang dilakukan oleh (Felania, 2016) (Tyas \& Kenny, 2016) (Nasib \& Amelia, 2018) (Indawati Lestari; Nasib, 2019) (Lestari, Nazah, Handayani, \& Wirda, 2020) (Fadli, 2020) yang menyatakan bahwa ketika brand image ditingkatkan maka akan meningkatkan customer retention. Implikasi temuan dalam penelitian ini lulusan dibekali 7 sertifikat adalah pilihan utama mahasiswa kuliah di Politeknik Unggul LP3M. Sehingga hal ini harus lebih diperhatikan khususnya manajemen dalam menyelenggaran kegiatan progam sertifikasi untuk lulusannya. (Indawati Lestari; Nasib, 2019) (Lestari et al., 2020)

\section{Pengaruh Brand Image Terhadap Customer Loyalty Melalui Customer Value}

Hasil dalam penelitian ini menunjukkan bahwa brand image tidak memiliki pengaruh tidak langsung terhadap customer loyalty melalui costomer value. Hasil tidak sesuai dengan hasil penelitian ini (Pramudyo, 2012) (Felania, 2016) (Khishandiri, Ariyanti, \& Irawan, 2010). Akan tetap penelitian ini sesuai dengan hasil penelitian (Hendrayana, 2014) (Fadli, 2020) (Lestari et al., 2020) yang menyatakan bahwa brand image tidak memiliki pengaruh tidak langsung terhadap customer loyalty melalui customer retention. Selanjutnya implikasi temuan dalam penelitian ini yaitu mahasiswa bersedia membela kampus Politeknik Unggul LP3M jika ada pihak lain yang menjelek-jelekkann. 


\section{Pengaruh Brand Image Terhadap Customer Loyalty Melalui Customer Retention}

Hasil penelitian ini menunjukkan bahwa brand image memiliki pengaruh tidak langsung terhadap customer loyalty melalui costomer value. Hasil penelitian ini mendukung penelitian sebelum yang dilakukan oleh (Felania, 2016)

(Indwati Lestari; Nasib, 2019) yang menyatakan bahwa ketika brand image ditingkatkan maka akan meningkatkan customer retention dan berdampak pada customer loyalty. Implikasi temuan dalam penelitian ini yaitu lulusan siap kerja adalah pilihan mahasiswa untuk kuliah di Politeknik Unggul LP3M.

\section{Simpulan}

Berdasarkan hasil penelitian dan pembahasan yang ada di atas, maka kesimpulan dalam penelitian ini yaitu sebagai berikut:

1. Secara langsung brand image berpengaruh signifikan terhadap customer value mahasiswa pada Politeknik Unggul LP3M.

2. Secara langsung brand image berpengaruh signifikan terhadap customer retention mahasiswa pada Politeknik Unggul LP3M.
3. Secara tidak langsung brand image tidak berpengaruh signifikan terhadap customer loyalty melalui customer value mahasiswa pada Politeknik Unggul LP3M.

4. Secara tidak langsung brand image berpengaruh signifikan terhadap customer.

Adapun Saran dalam penelitian ini yaitu sebagai berikut:

1. Brand image yang ada pada kampus Politeknik Unggul LP3M dapat menjaga untuk tidak menjual ijazah kepada masyarakat luas.

2. Custumer Value terus dipertahankan melalui evaluasi program sertifikasi keahlian setiap lulusan program studi. Diharapkan sertifikasi yang ada harus berstandar nasional.

3. Customer retention terus ditingkatkan melalui upaya membangun ikatan emosional kepada mahasiswa dan lulusan agar memiliki rasa cinta terhadap almamaternya.

\section{E. Daftar Pustaka}

Atstsaqifi, Y., D.W, H., \& Listyorini, S. (2014). Pengaruh Nilai Pelanggan, Citra Merek (Brand Image) dan Kualitas Pelayanan Terhadap Kepuasan Pelanggan Kereta Api Kelas Ekonomi Tawang Jaya Jurusan 
Semarang-Jakarta (Studi Kasus di Stasiun Poncol DAOP IV, Semarang). Diponegoro Journal of Social And Political Science, 1-10.

Felania. (2016). Pengaruh Mall Image Terhadap Customer Loyalty Dengan Customer Value Dan Customer Retention Sebagai Variabel Intervening Pada Mall Upper Class Di Surabaya. Jurnal Stategis Pemasaran, 1-9.

Hasan, A. (2013). Marketing Dan KasusKasus Pilihan. Yogyakarta: CAPS.

Hendrayana, A. S. (2014). Pengaruh Kualitas Pelayanan Dan Nilai Pelanggan Terhadap Citra Serta Dampaknya Pada Loyalitas Mahasiswa. Image, 141-153.

I, F. B., \& J, G. (2009). Epithelial Resealing. Int J Dev Biol: 1549-56.

Kartajaya, H. (2007). Hermawan kartajaya on Segmentation. Bandung: PT. Mizan Pustaka.

Khishandiri, A., Ariyanti, M., \& Irawan, H. (2010). Pengaruh Dimensi Kualitas Hubungan Terhadap Program Retensi Pelanggan Serta Implikasi Kedua Variabel Tersebut Dalam Mempengaruhi Loyalitas Pelanggan PT. Indosat Tbk Di Kota Bandung Tahun 2009. Jurnal Manajemen Indonesia, 135-148.

Kotler, P., \& Keller, L. (2012). Manajemen Pemasaran Jilid 1. Jakarta: Erlangga.

Nasib, \& Amelia, R. (2018). Pengaruh Kualitas Pelayanan, Harga Dan Citra Kampus Terhadap Loyalitas Mahasiswa Mengikuti Program Member Get Member (MGM) Melalui Kepuasan Mahasiswa Sebagai Variabel Intervening . Abdi Ilmu, 121-133.
Pramudyo, A. (2012). Pengaruh Citra Merek Terhadap Loyalitas Melalui Kepuasan Sebagai Variabel Intervening (Studi Pada Mahasiswa Perguruan Tinggi Swasta di Yogyakarta). JBMA, 1-16.

Pusparani, P. A., \& Rastini, N. M. (2014). Pengaruh Kualitas Produk Dan Brand Image Terhadap Kepuasan Konsumen Dan Loyalitas Pelanggan. Kamera Canon Digital Single Lens Reflex (DSLR) Di Kota Denpasar. Jurnal Hasil Riset, 1311-1319.

Soliha, S. (2015). Pengaruh Kualitas Produk Terhadap Nilai Pelanggan Dan Kepuasan Pelanggan Dan Dampaknya Pada Loyalitas Pelanggan Apotek Dela Semarang. Seminar Nasional \& Call Papers, (pp. 1-16).

Subagio, A. R. (2015). Pengaruh Atribut Produk Terhadap Keputusan Pembelian (Studi Pada Konsumen Produk Low Cost Green Car Astra Daihatsu Ayla di PT. Jolo Abadi, Malang). Malang: Universitas Brawijaya.

Tjiptono, F. (2011). Strategi Pemasaran. Yogyakarta: Andi.

Atstsaqifi, Y., D.W, H., \& Listyorini, S. (2014). Pengaruh Nilai Pelanggan, Citra Merek (Brand Image) dan Kualitas Pelayanan Terhadap Kepuasan Pelanggan Kereta Api Kelas Ekonomi Tawang Jaya Jurusan Semarang-Jakarta (Studi Kasus di Stasiun Poncol DAOP IV, Semarang). Diponegoro Journal of Social And Political Science, 1-10.

Felania. (2016). Pengaruh Mall Image Terhadap Customer Loyalty Dengan Customer Value Dan Customer Retention Sebagai Variabel Intervening Pada Mall Upper Class 
Di Surabaya. Jurnal Stategis Pemasaran, 1-9.

Hasan, A. (2013). Marketing Dan KasusKasus Pilihan. Yogyakarta: CAPS.

Hendrayana, A. S. (2014). Pengaruh Kualitas Pelayanan Dan Nilai Pelanggan Terhadap Citra Serta Dampaknya Pada Loyalitas Mahasiswa. Image, 141-153.

I, F. B., \& J, G. (2009). Epithelial Resealing. Int J Dev Biol: 1549-56.

Kartajaya, H. (2007). Hermawan kartajaya on Segmentation. Bandung: PT. Mizan Pustaka.

Khishandiri, A., Ariyanti, M., \& Irawan, H. (2010). Pengaruh Dimensi Kualitas Hubungan Terhadap Program Retensi Pelanggan Serta Implikasi Kedua Variabel Tersebut Dalam Mempengaruhi Loyalitas Pelanggan PT. Indosat Tbk Di Kota Bandung Tahun 2009. Jurnal Manajemen Indonesia, 135-148.

Kotler, P., \& Keller, L. (2012). Manajemen Pemasaran Jilid 1. Jakarta: Erlangga.

Nasib, \& Amelia, R. (2018). Pengaruh Kualitas Pelayanan, Harga Dan Citra Kampus Terhadap Loyalitas Mahasiswa Mengikuti Program Member Get Member (MGM) Melalui Kepuasan Mahasiswa Sebagai Variabel Intervening . Abdi Ilmu, 121-133.
Pramudyo, A. (2012). Pengaruh Citra Merek Terhadap Loyalitas Melalui Kepuasan Sebagai Variabel Intervening (Studi Pada Mahasiswa Perguruan Tinggi Swasta di Yogyakarta). JBMA, 1-16.

Pusparani, P. A., \& Rastini, N. M. (2014). Pengaruh Kualitas Produk Dan Brand Image Terhadap Kepuasan Konsumen Dan Loyalitas Pelanggan Kamera Canon Digital Single Lens Reflex (DSLR) Di Kota Denpasar. Jurnal Hasil Riset, 1311-1319.

Soliha, S. (2015). Pengaruh Kualitas Produk Terhadap Nilai Pelanggan Dan Kepuasan Pelanggan Dan Dampaknya Pada Loyalitas Pelanggan Apotek Dela Semarang. Seminar Nasional \& Call Papers, (pp. 1-16).

Subagio, A. R. (2015). Pengaruh Atribut Produk Terhadap Keputusan Pembelian (Studi Pada Konsumen Produk Low Cost Green Car Astra Daihatsu Ayla di PT. Jolo Abadi, Malang). Malang: Universitas Brawijaya.

Tjiptono, F. (2011). Strategi Pemasaran. Yogyakarta: Andi.

Tyas, A. A., \& Kenny, A. (2016). Pengaruh Srvice Quality Dan Brand Image Terhadap Loyalitas Melalui Kepuasan Konsumen Pada Inul Vtza Karoke Di Jakarta (Studi Kasus Pad Kepuasan Konsumen Inul Vitza Karoke Di Jakarta). Jurnal Ekonomi, 82-91. 